\title{
A School Nutrition Program Improves Vegetable and Fruit Knowledge, Preferences, and Exposure in First Nation Youth
}

\author{
A. Gates ${ }^{*, 1}$, R.M. Hanning ${ }^{1}$, M. Gates ${ }^{1}$, A.D. Isogai ${ }^{2}$, J. Metatawabin ${ }^{3}$ and L.J.S. Tsuji ${ }^{2}$ \\ ${ }^{I}$ University of Waterloo, Health Studies and Gerontology, Faculty of Applied Health Sciences, 200 University Ave. West, \\ Waterloo, Ontario N2L 3G1, Canada \\ ${ }^{2}$ University of Waterloo, Environment and Resource Studies, Faculty of Environment, 200 University Ave. West, Water- \\ loo, Ontario N2L 3G1, Canada \\ ${ }^{3}$ Peetabeck Academy, P.O. Box 211, Fort Albany, Ontario POL 1HO, Canada
}

\begin{abstract}
Addressing the high prevalence of overweight and obesity is a priority for Aboriginal youth. This study evaluated the implementation of a comprehensive school-wide vegetable and fruit program for grade six to eight First Nation students in Fort Albany, Ontario. The impact on nutrition knowledge and self-efficacy, and intentions to eat more vegetables and fruit was evaluated using the Knowledge, Self-efficacy, and Intentions questionnaire, adapted from the ProChildren Questionnaire. Evaluation also included focus groups with teachers and questionnaires for parents/guardians and students to assess satisfaction. In this sample of students, the program improved knowledge, exposure to, and preferences for vegetables and fruit, but did not impact intentions or self-efficacy. Thus, school nutrition programs may be popular and effective in shifting knowledge and preferences to consume healthy foods; however, no sustained benefit can be achieved without addressing barriers to access to affordable, healthy foods in remote communities.
\end{abstract}

Keywords: School, nutrition, education, adolescents, First Nation, vegetables and fruit.

\section{INTRODUCTION}

The prevalence of childhood and adolescent overweight and obesity has increased over the past 25 years in Canada, and continues to rise $[1,2]$. The problem is especially critical in Canadian Aboriginal populations; they have, in recent years, experienced drastic cultural and lifestyle changes that have lead to an epidemic of obesity more severe than in the general population $[3,6]$. Obesity, in turn, contributes to the heightened risk for Aboriginal people for type 2 diabetes, typically a condition of adult-onset, which is now being observed with increasing frequency in Aboriginal youth [7].

Although the etiology of childhood and adolescent obesity is multi-factorial, a poor diet and inadequate physical activity are two potentially modifiable contributors. Aboriginal people, in general, have poor intakes of vegetables and fruit, milk and alternatives, and grain products; "other" foods, those that are nutrient-poor and high in fat, sugar, and sodium, are often substituted for more healthy choices [4]. Research in Canadian and American populations has reported very poor vegetable and fruit consumption among Aboriginal youth $[8,9]$. Increasing vegetable and fruit intake is an important goal in interventions targeting childhood obesity in the Canadian Aboriginal population, as poor intakes have been associated with obesity $[10,11]$. Analogously, research in the First Nation (FN) community of Sandy Lake, Ontario, indicated that children who had greater fibre intakes were less likely to be overweight [12].

*Address correspondence to this author at the University of Waterloo, Health Studies and Gerontology, Faculty of Applied Health Sciences, 200 University Ave. West, Waterloo, Ontario N2L 3G1, Canada; Tel: 519-7728685; Fax: 519-746-2510; E-mail: agates@uwaterloo.ca
Improving the vegetable and fruit intakes of Aboriginal children is challenging due to the many barriers faced by Aboriginal families in terms of the procurement of healthy foods. Schools are a natural venue for addressing these barriers, as children generally spend six or more hours there per day, five-days-per week, and one-to-two meals are usually eaten there [13]. Effective school nutrition programs have the ability to empower students with the knowledge, attitudes, and skills required to make positive health decisions [13]. A recent European review by van Cauwenberghe and colleagues [14] concluded that there is strong evidence for multi-component school interventions to have a positive effect on vegetable and fruit intakes in children.

The current study investigates the impact of a pilot multicomponent school fruit and vegetable program in the remote, isolated FN community of Fort Albany, Ontario. Running from March to April 2010, the primary aim of the program was to improve nutrition knowledge, self-efficacy and intentions to consume a variety of vegetables and fruit.

\section{MATERIALS AND METHODOLOGY}

\section{Participants}

The program involved children in grades prekindergarten to eight at Peetabeck Academy, the FNadministered school in the community. Fort Albany is accessible only by air year-round, by barge or boat in the ice-free months, and by winter road after freeze-up. It is located on the south shore of the Albany River, 15 kilometers upstream from James Bay and 128 kilometers north of Moosonee, Ontario $[15,16]$. As with many remote, isolated FN communities of its size, living standards are poor [17]. The current 
study was conducted in partnership with Peetabeck Academy in Fort Albany FN, with permission from the Office of Research Ethics at the University of Waterloo. Passive parental consent procedures were used.

\section{Comprehensive School Vegetable and Fruit Program}

In 1996, the U.S. Centers for Disease Control and Prevention $(\mathrm{CDC})$ proposed a framework to guide successful school-based nutrition program development [18]. The CDC framework and a variety of other sources stress that comprehensive school nutrition programs should integrate a) health education, b) a healthy environment, c) healthy policy implementation, d) community and family involvement, and e) program evaluation [18-22]. In addition, physical education, healthy school food service, and training for teachers and staff are components not explicitly addressed through the current study.

\section{a) Health Education}

The program curriculum and parent information in the current study were modeled after the Northern Fruit and Vegetable Pilot Program (NFVPP) [23], and adapted to the needs of the community by the investigators and community advisors, including the school snack program coordinator. The comprehensive program was delivered by a senior undergraduate thesis student (Isogai, A) with previous teaching experience. Although it did not include formal training for teachers, the majority of teachers remained in the class to observe the lessons. The program involved 30-minute sessions per class that were integrated into the Ontario education curriculum [24], once per week, for five weeks. Each week, students were engaged in interactive lessons about vegetables and fruit, and were given informative handouts to bring home to their parents, including recipes and meal ideas.

\section{b, c) Healthy Environment/Policy}

The program also involved a healthy food provision component building on a snack program that has existed at the school for over 20 years. The snack program coordinator (Metatawabin, J) was provided with specific policy guidelines and a sample shopping list to aid in making healthy choices, adapted from recommendations from the Ontario Society of Nutrition Professionals in Public Health Steering Committee, the Cancer Care Ontario Healthy Eating Guidelines for School Nutrition Programs Pilot Project, and the Ontario Ministry of Education, by two registered dietitians $[21,25,26]$.

\section{d) Community and Family Involvement}

In the final week of the program, students were involved in a healthy eating community event, where they applied their knowledge by baking and distributing healthy pizzas. The event also included the following: a healthy traditional feast; a raffle for fresh produce, other healthy food items (e.g., milk, yogurt), and physical activity equipment; and recipes of the dishes served at the event. Extra raffle tickets were provided to parents/guardians who completed a paperbased questionnaire regarding satisfaction with the program. The feast included game meats provided by community members, which were incorporated into healthy dishes. Students and community members helped in food preparation as well as set-up, clean-up, and dish washing. The event was publicized via posters in key locations within the community.

\section{e) Program Evaluation}

All program materials were previewed during a formative evaluation with the school's snack program coordinator, to ensure the appropriateness of the program's components, culturally and otherwise. Suggested changes were completed before starting the program. Program integrity was documented by the undergraduate student delivering the lessons (including lesson content, participation rate, and inclassroom modification to the original program).

Changes in vegetable and fruit knowledge, intentions, and self-efficacy were evaluated using the paper-based Knowledge, Self-Efficacy, and Intentions Questionnaire (KSIQ). The KSIQ was adapted from the Pro Children questionnaire, which was first designed to assess the potential determinants of vegetable and fruit consumption in ten to 11 year old European children [27]. It included questions asking students to self-rate intake, knowledge, attitudes, liking, subjective norm, active parental encouragement, general selfefficacy, intention, habit, preferences, availability, and perceived barriers [27]. Although the questionnaire has not been validated in an Aboriginal population, a formative evaluation with the snack program coordinator aided in ensuring its appropriateness and confirming the face validity for students in Fort Albany FN. The KSIQ was administered in-class to all grade six to eight students, before and after the education program.

Student, teacher, and parent impressions of the program were gathered in order to guide future program delivery. Student impressions were gathered via open-ended questions answered online using the Web-Based Eating Behavior Questionnaire, developed at the University of Waterloo [28]. Teacher impressions were gathered during a focus group with the investigators (Gates, A; Gates, M) following program completion. Finally, parent impressions were gathered via a paper-based survey during the final community event component of the program. A Simple Measure of Gobbledygook (SMOG) test for readability on the parent questionnaire indicated a grade six reading level, so as to not exclude any community members [29]. A Cree translator was available for those who did not speak English.

\section{Data Analysis}

Statistical analyses were carried out using SPSS (Chicago, Illinois) version 17.0. The KSIQ was scored in terms of knowledge, intention/attitude, and self-efficacy questions, as well as the number of vegetables and fruit tried and liked pre- and post-program. Knowledge, intention/attitude, and self-efficacy sections of the questionnaire were scored out of eight, 18, and 16 points, respectively. Students were given a list of 40 vegetables and fruit to choose from in terms of having tried them and liking them, for a possible score of 40 for each of these sections. Changes in KSIQ responses pre- and post-program were evaluated using a one-tailed Wilcoxon signed-ranks test, as it was predicted that all scores would improve as a result of the program. The p-value of significance for all statistical analyses was $0.05(5 \%)$. Finally, focus group data were recorded in note form and summarized. 


\section{RESULTS}

\section{Knowledge, Self-Efficacy, and Intentions}

Thirty students in grades six to eight completed the preprogram KSIQ (77\% of students enrolled; $100 \%$ of students present at school). At post-program, 27 students were present to complete the KSIQ (69\% students enrolled; $100 \%$ students present at school). Eighteen students were included in the paired analysis to detect changes in responses postprogram as compared to pre-program (Table 1). Students showed significant improvements in nutrition knowledge $(p=0.003)$ and the number of vegetables and fruit that they had tried $(\mathrm{p}=0.004)$ and liked $(\mathrm{p}=0.003)$ post-program, as compared to pre-program (Table 2). No significant changes in intentions or self-efficacy to eat more vegetables and fruit were observed (Table 2).

\section{Program Integrity}

Overall, program attendance was $76 \%, 48 \%, 71 \%, 76 \%$, and $82 \%$ for weeks one through five, respectively. Attendance was poorest during the second week because many grade seven students were on a school trip. One lesson was not completed because student attention could not be maintained, possibly due to a lesson format that was not adequately engaging. Several lessons were modified to be more interactive, as this style of teaching was seen to be more effective by the student delivering the program. Other modifications were made to improve the program's cultural relevancy. Because of food availability, the variety of vegetables and fruit served in the school snack program was limited; however, policy guidelines were followed. Students generally received one to one-and-a-half servings of vegetables and fruit per day (usually apples or oranges, and juice). Otherwise, the program went as planned.

\section{Student Impressions}

Student impressions of the program were overwhelmingly positive $(n=10)$. Most students preferred the interactive lessons involving kinesthetic learning. One such lesson involved the preparation of healthy vegetable pizzas to teach students how to prepare healthy, homemade versions of their favourite foods. One student in the sixth grade said, "we all loved the pizza!"; while, another from grade seven said "I really liked the part where the class made pizzas". Another lesson involved the tasting of a number of vegetables and fruit, where students were asked to describe the colour, texture, taste, and smell of the vegetable or fruit, as well as their opinion. A sixth grade student said, "I liked trying new foods", another said, "I liked tasting new foods"; while, a third answered "making pizza and tasting food!" when asked about their favourite part of the program. Students also expressed a desire to learn more, saying they would like to know "how many fruits there are" and learn "about the benefits of vegetables and fruits".

\section{Teacher Impressions}

A focus group discussion revealed positive impressions of the program by those teachers who participated (June $2010 ; n=16$, response rate $94 \%$ ). Teachers echoed what was expressed by the students, one saying, "kids really liked the taste testing", with others agreeing. They saw special value in the tasting lesson as it exposed students to vegetables and fruit that they would otherwise not have the opportunity to try. One teacher noted that she saw a "huge difference" in

Table 1. Characteristics of the Study Population in the Comparison of Knowledge, Self-Efficacy, and Intentions Questionnaire Responses Pre- and Post-Program

\begin{tabular}{|c|c|c|c|}
\hline \multirow{2}{*}{ N } & Pre-program & Post-program & Pairs \\
\cline { 2 - 4 } & $\mathbf{3 0}$ & $\mathbf{2 7}$ & $\mathbf{1 8}$ \\
\hline \hline Mean age in years \pm SD & $12.9 \pm 0.9$ & $13.0 \pm 0.8$ & $13.0 \pm 0.9$ \\
\hline Male $(\%)$ & $18(60)$ & $12(44.4)$ & $11(61.1)$ \\
\hline Female $(\%)$ & $12(40)$ & $15(55.6)$ & $7(38.9)$ \\
\hline
\end{tabular}

Table 2. Comparison of Knowledge, Self-Efficacy, and Intentions Questionnaire Responses Pre- and Post-Program

\begin{tabular}{|c|c|c|c|c|c|}
\hline Intentions/Attitudes (18) & 9.5 & $8.7 \pm 3.3$ & 9.0 & $8.7 \pm 3.4$ & 0.479 \\
\hline Self-efficacy (16) & 8.0 & $7.4 \pm 2.9$ & 7.0 & $6.9 \pm 2.6$ & 0.089 \\
\hline Vegetables and fruit liked (40) & 20.0 & $18.8 \pm 6.7$ & 25.0 & $23.6 \pm 9.0$ & 0.003 \\
\hline
\end{tabular}


the students as a result of the program, in that they now knew the four food groups and were excited about nutrition. In terms of future initiatives, all teachers thought that the program should continue. One teacher expressed a need for more visual teaching materials and more teaching about the amounts of sugar in foods and type 2 diabetes. Although teachers were not formally trained, most stayed in the classroom to observe while lessons were being taught. However, teachers expressed a lack of time and energy to focus on nutrition and that having someone come to the class was most effective.

\section{Parent/Guardian Impressions}

Any community member present at the healthy feast who had a child attending the school was welcome to complete the survey $(n=47$; the sample would have been larger, but more surveys were not available). Parent/guardian impressions of the program were very positive. Of the parents/guardians who completed the questionnaire, $87 \%$ knew that the program existed. Seventy-three percent of parents/guardians reported that their child/children had either told them about or asked them to buy the vegetables and fruit they had tried at school. The major barriers to consuming vegetables and fruit expressed were that they were too expensive $(68 \%)$ and/or not fresh at the store (49\%). No parents/guardians reported disliking the taste of vegetables and fruit as being a barrier. In the words of one parent/guardian, "by the time they (vegetables and fruit) get here, they get rotten". Other parents/guardians said they would serve more vegetables and fruit at home "if there was a fresh stock at the store" or if there was "fresh produce and lower prices". Overall, $100 \%$ of parents/guardians thought the program should continue. In the words of one parent/guardian, "This is a good program for our problem, which some homes don't receive these kinda good healthy food"; while, another said that the program should continue because "I know there is good going into my children". Another said "I love this program. I think nutrition classes should happen more often"; while, one parent/guardian stated that "kids learn and are alert when they don't feel hungry". Parents/guardians also expressed a desire for more community events where fresh foods would be available at a reduced cost. The community feast was well attended (over 150 attendees) and parents/guardians expressed a need for future similar events. Most parents/guardians thought that the education material they had received through the program was useful. Some suggestions for information that could be included in the future included a "food programme for picky eaters" and information on "cost effective healthy foods".

\section{DISCUSSION}

The current study suggests that a multi-component school fruit and vegetable program improved the exposure of students at Peetabeck Academy in Fort Albany to a variety of vegetables and fruit, and enhanced their nutrition knowledge. What is interesting is that improved nutrition knowledge did not translate into improved intentions or self-efficacy to consume more vegetables and fruit (but see qualitative results). These findings are supported by a recent review by McClain and colleagues [30], which suggests that nutrition knowledge is not necessarily associated with healthy eating. Note, however, that although knowledge improved post-program, there is still room for improvement (mean 4.7 correct answers out of eight). Knowledge aside, research by Bihan and colleagues [31] suggested that a lack of financial means for purchasing vegetables and fruit was associated with poor vegetable and fruit intakes among a low-income French population. This is also likely the case in Fort Albany FN, due to high food insecurity rates and community level barriers to health eating as expressed by parents/guardians. If vegetables and fruit were readily available, of good quality, and affordable in the community, intentions and self-efficacy toward dietary change may have been higher. However, community-level barriers to healthy eating were not addressed by the program and should be the focus of future initiatives. Nevertheless, taste preferences for vegetables and fruit improved significantly post-program, and the school snack program is an invaluable resource for the promotion of healthy eating for the community's children [32].

Findings of the current study are supported by earlier research in Fort Albany by Skinner and colleagues [32], which identified the barriers and supports to healthy eating in the community via qualitative interviews and an environmental scan. Identified barriers included food insecurity related to the cost, availability, variety, and quality of foods available at the community store, lack of exposure to different foods, and remoteness, among others [32]. These same themes emerged in the responses to the parent questionnaires that were a part of the current study, and remain critical barriers to the improvement of diet quality in the community as a whole. Additionally, Skinner and colleagues [32] identified the school snack program, and the expansion of such programs, as important opportunities for healthy eating within the community. Although knowledge is not consistently associated with healthier eating [30], if the barriers concerning the cost and availability of healthy foods were reduced, the knowledge and taste preferences gained by students in this program may translate into improved intentions and selfefficacy to making healthier choices, potentially improving dietary intakes.

The program was very well received. The process evaluation revealed the need to be flexible and sensitive to culture. The classes that involved kinesthetic learning were most enjoyed by the students, and in future initiatives, interactive lessons would be encouraged as they were very well received and kept the attention of the students. The tasting sessions were also very well received by both students and teachers, and may have special relevance in remote, northern communities where a large variety of fresh produce is not normally available. A recent review by Cooke [33] indicated that children who have many opportunities to sample a variety of healthy foods from an early age tend to have healthier diets throughout childhood. Cooke's review suggests that simple food exposure may be enough to change food preferences [34]. The current study supports this finding, as the participating students had increased preferences for a variety of vegetables and fruit following the program.

Finally, although knowledge, self-efficacy, attitudes, and intentions are antecedent to behaviour change, and, hence, the results are encouraging, it must be noted that these act reciprocally with the environment [34]. While improving the school environment was a step in the right direction, it was not sufficient to improve intentions and self-efficacy to eat 
more vegetables and fruit. Community-level barriers to healthy eating in Fort Albany FN, including inadequate and inconsistent access to healthy foods at a reasonable cost, likely impeded health behaviour change in the context of this study. However, the improvements in knowledge and exposure to healthy foods in the students participating in the current study are encouraging. Lessons learned in the current study will be of particular value in future initiatives with this population and similar ones. It is recommended that the current study be replicated in other remote $\mathrm{FN}$ communities in order to test the robustness of our results. With larger sample sizes, 24-hour dietary recall or food frequency data may be useful to assess changes in dietary intakes.

\section{CONCLUSION}

The program examined in this study was well received by students, parents, and teachers. It significantly improved exposure to and preferences for vegetables and fruit in the participating students. However, it did not improve intentions nor self-efficacy to consume vegetables and fruit, likely due to the short duration and moderate intensity of the intervention, and community-level barriers to healthy eating. Nevertheless, there have been few comprehensive school nutrition programs in remote FN communities. The current study emphasizes the appeal of such programs and the potential to positively influence food exposure and knowledge. In the face of community level barriers to healthy eating, the importance of school nutrition programs in remote, isolated FN communities cannot be denied.

\section{ACKNOWLEDGEMENTS}

This work was supported by the Canadian Institutes of Health Research, Canada's Research-Based Pharmaceutical Companies Health Research Foundation, Health Canada's First Nations and Inuit Health Branch, the Danone Institute of Canada, and the Ontario Ministry of Research and Innovation. Master's studentship awards from the Heart and Stroke Foundation of Ontario were greatly appreciated. We would like to acknowledge the contributions of Dr. Dan McCarthy in data collection, and statistical advice of Dr. Ian Martin. Lastly, we would like to thank Peetabeck Academy in Fort Albany FN for their collaboration and participation in this research.

\section{REFERENCES}

[1] Shields M. Nutrition: Findings from the Canadian Community Health Survey - overweight Canadian children and adolescents. Statistics Canada 2005; 82-620-MWE: 2-34.

[2] Public Health Agency of Canada. Obesity in Canada - Snapshot. 2009. Retrieved July 20, 2010 from http://www.phacaspc.gc.ca/publicat/2009/oc/index-eng.php\#tot

[3] Canadian Paediatric Society. Risk reduction for type 2 diabetes in Aboriginal children in Canada. Paediatr Child Health 2005; 10: 4952.

[4] Garriguet D. Obesity and the eating habits of the Aboriginal population. Health Rep 2008; 19: 1-15.

[5] Tjepkema M. Adult obesity. Health Rep 2006; 17: 9-25.

[6] Tremblay MS, Perez CE, Ardern CI et al. Obesity, overweight and ethnicity. Health Rep 2005; 16: 23-34.

[7] Kmetic A, Reading J, Estey E. Taking a life course perspective on cardiovascular disease and diabetes in First Nations peoples. CJNR $2008 ; 40 ; 58-78$.
[8] Downs SM, Arnold A, Marshall D et al. Associations among the food environment, diet quality and weight status in Cree children in Quebec. Public Health Nutr 2009; 12: 1504-11.

[9] Di Noia J, Schinke SP, Contento IR. Dietary patterns of reservation and non-reservation Native American youths. Ethn Dis 2005; 15: 705-12.

[10] Shields M. Nutrition: Findings from the Canadian Community Health Survey - overweight Canadian children and adolescents. Statistics Canada 2005; 82-620-MWE: 2-34.

[11] Vanasse A, Demers M, Hemiari A et al. Obesity in Canada: where and how many? Int J Obes (Lond) 2006; 30: 677-83.

[12] Hanley AJ, Harris SB, Gittlesohn J et al. Overweight among children and adolescents in a Native Canadian community: prevalence and associated factors. Am J Clin Nutr 2000; 71: 693-700.

[13] Budd GM, Volpe SL. School-based obesity prevention: research, challenges, and recommendations. J Sch Health 2006; 76: 485-95.

[14] Van Cauwenberghe E, Maes L, Spittaels H et al. Effectiveness of school-based interventions in Europe to promote healthy nutrition in children and adolescents: systematic review of published and 'grey' literature. Br J Nutr 2010; 103: 781-97.

[15] Chiefs of Ontario. Community Profiles. 2005. Retrieved January 25, 2010; Available from http://www.chiefs-pf-ontario.org/profiles

[16] Five Nations Energy. Community Profiles. 2005. Retrieved January 25, 2010; Available from http://www.fivenations.ca

[17] Fort Albany First Nation. Fort Albany First Nation Community Profile. 1999. Retrieved January 25, 2010; Available from http://www.wakenagun.ca/PDF/Fort\%20Albany\%20Profile.pdf

[18] Centers for Disease Control and Prevention. Guidelines for school health programs to promote lifelong healthy eating. MMWR CDC Surveill Summ 1996; 45: 1-42.

[19] Veugelers PJ, Fitzgerald AL. Effectiveness of school programs in preventing childhood obesity: a multilevel comparison. Am J Public Health 2005; 95: 432-5.

[20] Brant County Health Unit. Creating a healthy school nutrition environment. A resource for school decision makers. 2005. Retrieved May 22, 2009, Available from www.bchu.org/pdf/healthy_school_environment.pdf

[21] Ontario Society of Nutrition Professionals in Public Health School Nutrition Workgroup Steering Committee. Call to action: creating a healthy school nutrition environment. 2004. Retrieved June 9, 2009 from; http://www.osnpph.on.ca/resources/index.php

[22] Perez-Rodrigo C, Aranceta J. School-based nutrition education: lessons learned and new perspectives. Public Health Nutr 2001; 4: 131-9.

[23] He M, Beynon C, Sangster Bouck M et al. Northern fruit and vegetable pilot program: Final report. London, Ontario: MiddlesexLondon Health Unit 2007.

[24] Ontario Ministry of Education. The Ontario Curriculum. 2009. Retrieved January 18, 2010; Available from http://www.edu.gov.on.ca/eng/curriculum/elementary/grades.html

[25] Cancer Care Ontario. Healthy Eating Guidelines for School Nutrition Programs Pilot Project. Toronto: Aboriginal Cancer \& Prevention Team 2010.

[26] Ontario Ministry of Education. Appendix: Nutrition Standards for Ontario Schools. 2010. Retrieved January 18, 2010; Available from http://www.edu.gov.on/extra/eng/ppm/150.html

[27] De Bourdeaudhuij I, Klepp K-I, Due P et al. Reliability and validity of a questionnaire to measure personal, social and environmental correlates of fruit and vegetable intake in 10-11-year-old children in five European countries. Public Health Nutr 2005; 8: 189-200.

[28] Hanning RM, Royall D, Toews J et al. Web-based food behaviour questionnaire: validation with grades six to eight students. Can J Diet Pract Res 2009; 70: 172-8.

[29] Government of South Australia. Readability Tools. 2006. Retrieved July 20, 2010; Available from www.chdf.org.au/library/Readable\%20health\%20info.pdf 
[30] McClain AD, Chappuis C, Nguyen-Rodriguez ST et al. Psychosocial correlates of eating behaviour in children and adolescents: a review. Int J Behav Nutr Phys Act 2009; 12: 54.

[31] Bihan H, Castetbon K, Mejean C et al. Sociodemographic factors and attitudes toward food affordability and health are associated with fruit and vegetable consumption in a low-income French population. J Nutr 2010; 140: 823-30.
[32] Skinner K, Hanning RM, Tsuji LJS. Barriers and supports for healthy eating and physical activity for First Nations youth in northern Canada. Int J Circumpolar Health 2006; 65: 148-61.

[33] Cooke L. The importance of exposure for healthy eating in the childhood: a review. J Hum Nutr Diet 2007; 20: 294-301.

[34] Bandura A. Health promotion by social cognitive means. Health Educ Behav 2004; 31: 143-164.

(C) Gates et al.; Licensee Bentham Open

This is an open access article licensed under the terms of the Creative Commons Attribution Non-Commercial License (http://creativecommons.org/licenses/by-nc/3.0/) which permits unrestricted, non-commercial use, distribution and reproduction in any medium, provided the work is properly cited. 